Article

\title{
Insecticidal Efficacy of Microbial-Mediated Synthesized Copper Nano-Pesticide against Insect Pests and Non-Target Organisms
}

\author{
Perumal Vivekanandhan $1,2, *\left(\mathbb{0}\right.$, Kannan Swathy ${ }^{1,2}$, Adelina Thomas ${ }^{3}\left(\mathbb{C}\right.$, Eliningaya J. Kweka ${ }^{4,5}(\mathbb{D}$, \\ Afroja Rahman ${ }^{6}$, Sarayut Pittarate ${ }^{6}$ and Patcharin Krutmuang $6,7,8, * \mathbb{D}$ \\ 1 Society for Research and Initiatives for Sustainable Technologies and Institutions, Grambharti, Amarapur, \\ Gandhinagar 382650, Gujarat, India; Swathykannan.23@gmail.com \\ 2 Department of Biotechnology, Periyar University, Salem 636011, Tamil Nadu, India \\ 3 School of Pharmacy, Catholic University of Health and Allied Sciences, Mwanza P.O. Box 1464, Tanzania; \\ adelinathomas45@gmail.com \\ 4 Division of Livestock and Human Diseases Vector Control, Tropical Pesticides Research Institute, \\ Arusha P.O. Box 3024, Tanzania; pat.kweka@gmail.com \\ 5 Department of Medical Parasitology and Entomology, Catholic University of Health and Allied Sciences, \\ Mwanza P.O. Box 1464, Tanzania \\ 6 Department of Entomology and Plant Pathology, Faculty of Agriculture, Chiang Mai University, \\ Chiang Mai 50200, Thailand; afroja_r@cmu.ac.th (A.R.); sarayut_pit@cmu.ac.th (S.P.) \\ 7 Innovative Agriculture Research Center, Faculty of Agriculture, Chiang Mai University, \\ Chiang Mai 50200, Thailand \\ 8 Research Center of Microbial Diversity and Sustainable Utilization, Faculty of Science, Chiang Mai University, \\ Chiang Mai 50200, Thailand \\ updates \\ * Correspondence: mosqvk@gmail.com (P.V.); patcharink26@gmail.com (P.K.)
}

Citation: Vivekanandhan, P. Swathy, K.; Thomas, A.; Kweka, E.J.; Rahman, A.; Pittarate, S.;

Krutmuang, P. Insecticidal Efficacy of Microbial-Mediated Synthesized Copper Nano-Pesticide against Insect Pests and Non-Target Organisms. Int J. Environ. Res. Public Health 2021, 18, 10536. https://doi.org/10.3390/ ijerph181910536

Academic Editor: Woo-Sung Kwon

Received: 24 June 2021

Accepted: 23 July 2021

Published: 8 October 2021

Publisher's Note: MDPI stays neutral with regard to jurisdictional claims in published maps and institutional affiliations.

Copyright: (c) 2021 by the authors. Licensee MDPI, Basel, Switzerland. This article is an open access article distributed under the terms and conditions of the Creative Commons Attribution (CC BY) license (https:// creativecommons.org/licenses/by/ $4.0 /)$
Abstract: Currently, medical and stored grain pests are major concerns of public health and economies worldwide. The synthetic pesticides cause several side effects to human and non-target organisms. Copper nanoparticles (CuNPs) were synthesized from an aqueous extract of Metarhizium robertsii and screened for insecticidal activity against Anopheles stephensi, Aedes aegypti, Culex quinquefasciatus, Tenebrio molitor and other non-target organisms such as Artemia salina, Artemia nauplii, Eudrilus eugeniae and Eudrilus andrei. The synthesized copper nano-particles were characterized using, UV-vis spectrophotometer, Fourier Transform Infrared Spectroscopy (FTIR), X-Ray Diffraction (XRD), Energy Dispersive X-Ray analysis (EDaX), High Resolution Scanning Electron Microscope (HR-SEM) and Atomic Force Microscope (AFM) analysis. Insects were exposed to $25 \mu \mathrm{g} / \mathrm{mL}$ concentration produced significant mortality against larvae of A. stephensi, A. aegypti, C. quinquefasciatus and T. molitor. The lower toxicity was observed on non-target organisms. Results showed that, M. robertsii mediated synthesized CuNPs is highly toxic to targeted pests while they had lower toxicity were observed on non-target organisms.

Keywords: Metarhizium robertsii; CuNPs; Artemia salina; Eudrilus eugeniae; Eudrilus andrei; Artemia nauplii; Tenebrio molitor; Mosquitoes

\section{Introduction}

Mosquito vectors are distributed abundantly in tropical and sub-tropical regions and transmitting several pathogens to humans and animals. They transmit several vector borne diseases including, dengue, malaria, yellow fever, filariasis and recently zika virus [1]. Malaria is caused by the Plasmodium parasite carried by female Anopheles mosquitoes, filariasis by female Culex and Anopheles mosquitoes while dengue, yellow fever and zika are transmitted by Aedes pp. [2,3]. Tenebrio molitor (Coleoptera: Tenebrionidae) is a stored grain pest [4]. It also damage to several economically important food grains such as, Zea mays, Glycine max, Triticum aestivum [5]. T. Molitor caused 20\% yearly losses in stored grains product in worldwide [6]. 
Synthetic chemical pesticides such as carbamates, organophosphorus, organochlorines and temephos are mainly to control medical and agricultural pests [3,7]. The repeated usage of chemicals resulted into significant drawbacks and challenges in pest control programme. Thus searching for alternative low cost pesticides, that are eco-friendly, effective and safe for the management of the medical and stored grain pests is essential [8-10].

Insect pathogenic fungi are cosmopolitan in nature and also non-virulent to humans and other beneficial organisms [11]. Simultaneously, entomopathogenic fungi have shown to be more effective with minimal dosages to mosquitoes and coleopteran pests [12]. Previous research shown that, Beauveria sp., Metarhizium sp., Aspergillus sp., and Fusarium sp., conidia and their chemical constituents have produced remarkable insecticidal activity on different mosquito vectors $[2,3,8-10,13]$. Entomopathogenic fungal derived secondary metabolites conjugated with metal nanoparticles are recommended, are eco-friendly and an improved method for disease vector control $[3,14]$. Eco-friendly synthesized nanoparticles using botanicals, insect pathogenic fungi and bacteria are cost effective, and target specific for vector control [15]. Copper nanoparticles have a major impact on insect antioxidants and detoxifying enzyme systems. They affect enzymes that are connected to oxidative stress resulting in cell death in insects. In insects, metal nanopesticides bind to $\mathrm{S} \& \mathrm{P}$ protein, DNA and decreases cell membrane permeability resulting into mosquito death $[8,16]$. Metarhizium fungi are one of the most common insect pathogenic fungi; it is soil-borne and infects mainly to medical and agricultural pests that are found in the soil. Recently, M. anisopliae has been used as microbial pesticides for controlling medical and agricultural pests. Their conidia produced remarkable mortality under laboratory and field conditions $[3,17]$. There are no toxicological or pathological symptoms observed in birds, fish, mice, rats, and guinea pigs following exposure to M. anisopliae conidia [18].The entomopathogenic fungi do not cause any risk to humans and the environment [19].

Earthworms are important components of soil ecosystems and are recognized as decomposers in the development of soil macro and micro nutrition. Frequently exposed to synthetic chemical insecticides in the soil, the earthworm will indicate the soil contaminations [20]. Earthworms are also considered as determinants and indicators of soil pollution and fertility [2,3]. They are also an indicator species for various toxicology evaluations [2]. Eudrilus sp., are in soils enriched with organic matter [21]. Similarly, Brine shrimp Artemia sp.(Anostraca: Artemiidae) are branchiopod crustaceans that tolerate salinity ranging from 4 to $250 \mathrm{gL}^{-1}$. Since they are sensitive to chemicals or other toxicants in aquatic environment, they are widely used for the evaluation of the marine contamination by synthetic chemicals. For example, A. nauplii and A. salina are important components of aquatic ecosystems and considered as biomarkers for environmental toxicity [22]. Metarhizium robertsii has not been tested for the green synthesis of metal nanoparticles against medical and stored grain pests. In this research, we evaluated the acute toxicity of copper nanoparticles synthesized with $M$. robertsii against larvae of A. stephensi, A. aegypti and C. quinquefasciatus, T. molitor and non-target organisms such as A. salina, A. nauplii. E. eugeniae and E. andrei.

\section{Materials and Methods}

\subsection{Fungal Culture}

Metarhizium robertsii was isolated from agricultural soils at Sanarappatti, Tamil Nadu, India (12.0933_N, 78.2020_E) (Figure 1A). Insect pathogenic fungi were recovered using the insect bait method with (Galleria mellonella) [2,23]. Fifteen early 3rd instar G. mellonella were transferred into a plastic box ( $5 \mathrm{~cm}$ height $\times 8 \mathrm{~cm}$ bottom $\times 12 \mathrm{~cm}$ top) contained $250 \mathrm{~g}$ of soil. The soil samples have three replicates which were performed. After transfer of the larvae, the containers were closed with lids and incubated at room temperature $\left(28 \pm 2{ }^{\circ} \mathrm{C} ; 85 \% \mathrm{RH}\right)$. Each plastic box was examined twice per day for 15 days and dead insect larvae were removed from the containers. They were surface-sterilized for $15 \mathrm{~min}$ with $70 \%$ ethanol then rinsed in sterile deionized water and then air dried. The insect cadaver was placed on PDA (Potato Dextrose Agar, HiMedia, Maharashtra, India) medium. They were incubated at $28 \pm 2{ }^{\circ} \mathrm{C} ; 80 \% \mathrm{RH}$ for 3 days. 


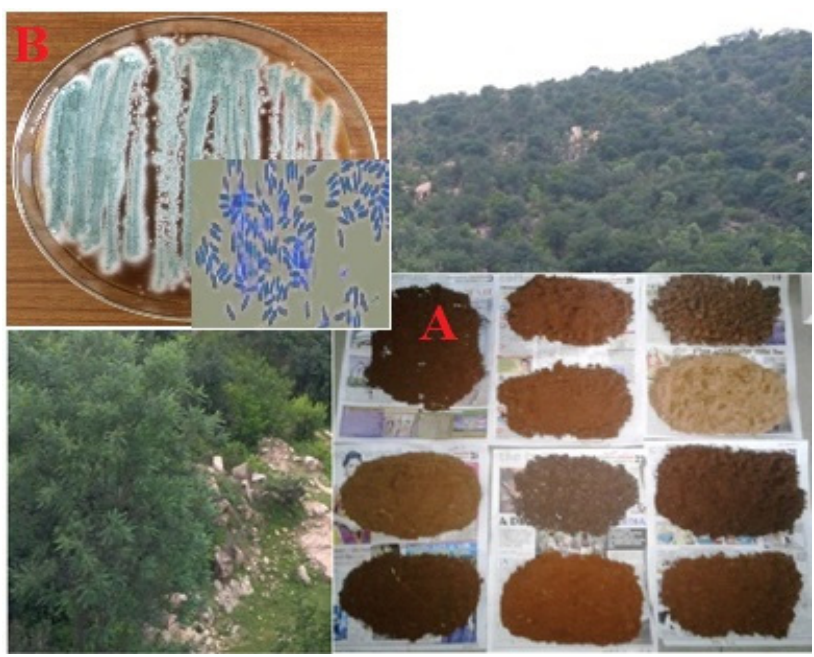

Figure 1. (A) Soil collection area and soil sample and (B) Metarhizium robertsii insect pathogenic fungi.

The entomopathogenic fungi was sub-cultured on PDA medium and incubated for $8-12$ days at $26 \pm 2{ }^{\circ} \mathrm{C}$. The pure culture of insect pathogenic fungi was then incubated in a BOD incubator (Kesar Control Systems, Gujarat, India) at $35 \pm 2{ }^{\circ} \mathrm{C}$ for further use.

\subsection{Morphological Confirmation Fungi}

The fungal morphological recognition was done based on morphological features such as fungal mycelia color, aerial structures, color making and conidial structure. The fungi were stained with lacto-phenol cotton blue and viewed under light microscope (OlympusCH20i, Mumbai, India) at 40× magnification.

\subsection{Fungal Broth Culture}

The fungal broth was prepared using the method of $[8,24]$. Cultures were grown on PDA in $250 \mathrm{~mL}$ culture flasks. The flasks contained $150 \mathrm{~mL}$ of Potato Dextrose Broth (PDB), in which $0.7 \mathrm{~g} / \mathrm{mL}$ chloramphenicol was added as a bacteriogenic agent. Then $1 \times 10^{6}$ spores $/ \mathrm{mL}$ was inoculated into the broth. After inoculation, the medium was incubated at $28 \pm 2{ }^{\circ} \mathrm{C}$ for 12 days.

\subsection{Genomic DNA Extraction}

The fungal immature biomass was cultivated in $50 \mathrm{~mL}$ fungi medium (SDB, HiMedia, India). The $1 \times 10^{9}$ conidia $/ \mathrm{mL}$ was transferred into culturing medium. After, the conidia inoculation media were incubated at $28 \pm 1{ }^{\circ} \mathrm{C}$ for 6 days. After incubation time, the mycelia were filtered through filter paper and the immature mats were taken for genomic DNA extraction [2,24]. Then, $5 \mathrm{mg}$ of fungi biomass was ruptured in a mortar and pestle with liquid nitrogen. Subsequent to rupturing, $1.5 \mathrm{~mL}$ CTAB buffer was added to rupture the mycelia then mixed and transferred to new tubes. The test tubes were moved to a water bath at $60^{\circ} \mathrm{C}$ for $40-50 \mathrm{~min}$. After incubation, the $2.5 \mathrm{~mL}$ tubes were transferred to $4{ }^{\circ} \mathrm{C}$ for $20 \mathrm{~min}$, after which centrifugation at $7000 \mathrm{rpm}$ was performed for $15 \mathrm{~min}$. The aqueous part was transferred to new test tubes, then an equivalent amount of chloroform and isoamyl alcohol (23:2) was made and softly mixed in. The resultant mixture was centrifuged at 13,000 rpm for $12 \mathrm{~min}$, the pellet was removed, and the upper part collected in a separate tube. The same amount $(1 \mathrm{~mL})$ of ice-cold isopropanol with $90 \%$ ethanol was added to the test tubes and mixed. Then, it was being incubated at $28^{\circ} \mathrm{C}$ for $50 \mathrm{~min}$. After incubation, the test tubes were centrifuged at 13,000 rpm for $15 \mathrm{~min}$. Genomic DNA pellets were collected from the centrifuged test tubes and the upper phase was discarded. Genomic DNA was cleaned with 75\% ethanol and dried. Purified genomic DNA was taken for further study. 


\subsection{Genomic DNA Purity Confirmation}

Insect pathogenic fungal genomic DNA purity was confirmed by using $0.8 \%$ agarose gel electrophoresis (HiMedia, Maharashtra, India).

\subsection{PCR Amplification}

The 18s rDNA common primer was used for fungal genomic DNA amplification. PCR reactions were carried out in a $20 \mu \mathrm{L}$ response volume, which contained $1 X$ PCR buffer with $1.5 \mathrm{mM} \mathrm{MgCl}, 0.2 \mathrm{mM}$ each of dNTPs (dATP, dGTP, dCTP and dTTP), $1 \mu \mathrm{L}$ DNA, $0.2 \mu \mathrm{L}$ Phire Hotstart II DNA polymerase enzyme, $0.1 \mathrm{mg} / \mathrm{mL}$ BSA, 3\% DMSO, $0.5 \mathrm{M}$ betaine and $5 \mu \mathrm{L}$ of forward and reverse primers. Polymerase chain reaction temperatures were followed in the early stage at $95^{\circ} \mathrm{C}$ for $5 \mathrm{~min}$; denaturing at $94^{\circ} \mathrm{C}$ for $30^{\circ} \mathrm{C}$ and annealing temperature was $50{ }^{\circ} \mathrm{C}$ for $30 \mathrm{~s}$; elongation temperature at $72{ }^{\circ} \mathrm{C}$ for $2 \mathrm{~min}$ and extension temperature at $72{ }^{\circ} \mathrm{C}$ for $7 \mathrm{~min}$.

\subsection{Sequence Analysis}

Sequence was checked using a sequence scanner software version1.0 (Applied Biosystem, Sudbury, ON, Canada). Fungal sequence restriction and arrangement were done by using Geneious professional version-5.1.0 software (Applied Biosystem, Sudbury, ON, Canada).

\subsection{Fungal Aqueous Extract}

Fifty grams of fungal biomass was cleaned twice with sterile $\mathrm{H}_{2} \mathrm{O}$ then put in a $250 \mathrm{~mL}$ glass beaker that contained $150 \mathrm{~mL}$ of sterile distilled water and held for 5 days followed by a cooling extraction [10]. After 5 days, the aqueous secondary metabolites were filtered using Whatman no. 1 filter paper (HiMedia, Maharashtra, India).

\subsection{Synthesis of Copper Nanoparticles (CuNPs)}

Fifteen $\mathrm{mL}$ of fungal culture filtrate was transferred to $85 \mathrm{~mL}$ of $1 \mathrm{mM}$ copper sulphate solution mixed properly and heated at $60^{\circ} \mathrm{C}$ using a hot plate magnetic stirrer (LabFriend India Private Limited, New Delhi, India). After this process, the solution was incubated in dark conditions at $28 \pm 2{ }^{\circ} \mathrm{C}$ for $72 \mathrm{~h}$ and the color changed into a dark brown. Then, the solution was filtered with Whatman no. 1 filter paper, and the solution is washed with double distilled water using centrifugation (Kesar Control Systems, Gujarat, India) with a range at 11,000 rpm for $8 \mathrm{~min}$. The washing measures were repeated many times until the unwanted particles were removed. Finally, the pellet was dried in room temperature for two days and pellets were used for all the experiments and all spectroscopic studies.

\subsection{Characterization of $\mathrm{CuNPs}$ Nanoparticles}

Insect pathogenic fungal-derived copper nanoparticles were characterized using UVVis spectrophotometer(Cole-Parmer India Pvt. Ltd., Mumbai, India), Fourier Transform Infrared Spectroscopy (FTIR) (PerkinElmer, Waltham, MA, USA), X-ray Diffraction (XRD) (M/S Virtue Meta-Sol, Hyderabad, India), Energy Dispersive X-ray analysis (EDaX) (Jeol, Tokyo, Japan), High Resolution Scanning Electron Microscope (HR-SEM) (Hitachi India Pvt. Ltd., Gujarat, India) and Atomic Force Microscope (AFM) (Nano Science and Technology Company, Uttar Pradesh, India) analysis.

\subsection{Mosquito Rearing}

A. stephensi, A. aegypti and C. quinquefasciatus larvae were obtained from the Institute of Vector Control Zoonoses, Hosur, Tamil Nadu, India and were maintained in the laboratory. Larval bioassays were done at $28 \pm 2{ }^{\circ} \mathrm{C}, 70-80 \% \mathrm{RH}$ and a 14:10 light-dark photoperiod. Larvae were fed with millet powder [2]. 


\subsection{Stored Grain Pests}

The Tenebrio molitor culture was held in the laboratory at $28 \pm 2{ }^{\circ} \mathrm{C}, 70-80 \% \mathrm{RH}$ with a 14:10 light-dark photoperiod. The larvae were reared in a plastic container $(55 \mathrm{~cm}$ long $\times 38 \mathrm{~cm}$ wide $\times 10 \mathrm{~cm}$ height) and fed with wheat bran containing a rich source of macro and micro nutrition. The healthy 4 th instar was used for bioassays in the laboratory.

\subsection{Tenebrio molitor Larval Bioassay}

The insect pathogenic fungal-derived CuNPs was determined by calculating the lethal concentration $\left(\mathrm{LC}_{50}\right.$ and $\left.\mathrm{LC}_{90}\right)$ values and evaluated with five different concentrations $(2-25 \mu \mathrm{g} / \mathrm{mL})$. Each concentration had three replicates and each replicate had 25, 4th instar T. molitor. Different concentrations of the fungal-derived CuNPs were applied in a food diet to the larva. The dead T. molitor larvae were counted $24 \mathrm{~h}$ after treatment.

\subsection{Earthworm Culture}

E. eugeniae and E. andrei are bio-indicators of soil pollution. They were maintained in laboratory conditions at $28 \pm 1{ }^{\circ} \mathrm{C}$ [3].

\subsection{Artemia Species Culture}

A. nauplii and A. salina larvae were reared in the laboratory in $1000 \mathrm{~mL}$ of seawater with a salinity of $30 \mathrm{ppt}$ and the $\mathrm{pH}$ was maintained at 8-8.5 with a 17:7 (L:D) photoperiod. The temperature was maintained at $25 \pm 3{ }^{\circ} \mathrm{C}$. Aeration was provided every $24 \mathrm{~h}$ with an aspirator.

\subsection{CuNPs Mosquito Larval Toxicity Assay}

Larval bioassays were done using the method of the World Health Organization [25]. Five different concentrations from $5-25 \mu \mathrm{g} / \mathrm{mL}$ were tested using 25 , 4 th instar A. aegypti, $A$. stephensi and C. quinquefasciatus. For each concentration, there were three replicates and in each replicate, 25 larvae were used. The negative control was used as dechlorinated tap water. After $24 \mathrm{~h}$ post treatment, the dead larvae were recorded and probit analysis was done using SPSS 16.00, (IBM, New York, NY, USA).

\subsection{Artificial Soil Assay}

Artificial soil comprised of $15 \%$ sphagnum peat, $25 \%$ kaolinite clay and $75 \%$ fine soil was included for evaluation. This was done according to OECD guidelines with slight modifications $[3,26]$. A few drops of $\mathrm{CaCO}_{3}$ were added to assay to regulate the $\mathrm{pH}$ to $6.0 \pm 0.5$. Soil water content was maintained at $30 \%$. The soil was prepared by adding different concentrations of CuNPs $(250 \mathrm{mg} / \mathrm{kg})$ on a dry weight basis. Fifteen adult E. eugeniae and E. andrei were transferred to $1000 \mathrm{~g}$ of test substrate, each with the desired concentration. The bioassay containers were closed with a lid to prevent the E. eugeniae and E. andrei escaping. Thirty days after treatment, the dead E. eugeniae and E. andrei were counted. Each concentration had three replicates and each replicate had 15 earthworms. The control was not treated with any CuNPs.

\subsection{CuNPs'Toxicity on Artemia Species}

Mature A. nauplii and A. salina were collected with a micropipette and used for toxicity assays with different test concentrations $(5-25 \mu \mathrm{g} / \mathrm{mL})$ of $M$. robertsii-derived CuNPs. Sterile seawater was used as a negative control. A. nauplii and A. salina $\mathrm{LC}_{50}$ and $\mathrm{LC}_{90}$ values were calculated at $24 \mathrm{~h}$ after treatment and the experiment was replicated 3 times for each concentration. After treatment, the A. nauplii were observed under binocular microscope for observation of morphological changes.

\subsection{Histopathological Study}

Thirty days after treatment, the CuNPs' exposed and unexposed E. eugeniae and E. andrei were separately fixed with $5 \%$ formalin for $4 \mathrm{~h}$ at $4{ }^{\circ} \mathrm{C}$. Blocks were chilled at 
$25{ }^{\circ} \mathrm{C}$ for $2 \mathrm{~h}$ then sliced into $4 \mu \mathrm{m}$ thinness, with $1.0 \mathrm{~mm}$ ribbons, using a microtome (Leica, Germany). The sectioned E. eugeniae and E. andrei were stained with Ehrlich's haematoxylin and eosin, and after drying, the slides were observed under a light microscope (OlympusCH20i/India) at $40 \times$ magnification.

\subsection{Ethical Statement}

This article does not contain any studies with human participants performed by any of the authors. All applicable international, national, and institutional guidelines for the care and use of animals were followed.

\subsection{Statistical Analysis}

Mortalities of target and non-target species were adjusted using Abbott's formula, [27]. The experimental dosage was determined by utilizing probit analysis and the values expressed as means \pm standard (SE) error of three replicates. The lethal concentrations required to kill $50 \%$ and $90 \%\left(\mathrm{LC}_{50}\right.$ and $\left.\mathrm{LC}_{90}\right)$, and chi-square test were calculated using the SPSS (Statistical Package of Social Sciences) software version 16.0, (IBM, New York, NY, USA).

\section{Results}

\subsection{Microscopic Confirmation}

The microscopic confirmation of insect pathogenic fungi color appearance is light green; the conidial structure was slender in shape. Based on first round morphological structures, the isolated fungi were confirmed as Metarhizium species (Figure 1B).

\subsection{Molecular Confirmation and Phylogenetic Construction}

The $M$. robertsii genomic DNA purity was identified in $0.8 \%$ agarose gel and fungal genomic DNA was amplified using 18s rDNA primer. The amplified DNA size range was $900 \mathrm{bp}$. The sequence was deposited in the GenBank database (NCBI), and the accession number was MK719963.1. Results of deposited 18s rDNA sequence showed a 100\% similarity with Metarhizium robertsii. Thus, morphological and molecular studies results confirmed that the isolated entomopathogenic fungi as $M$. robertsii. The neighborjoining tree methods were done for evolutionary confirmation of $M$. robertsii (Figure 2).

\subsection{Synthesis and Confirmation of CuNPs}

The M. robertsii fungal filtrate from CuNPs showed a dark brown color to light blue thus revealing the reduction of $1 \mathrm{mM}$ of copper sulphate $\left(\mathrm{CuSO}_{4}\right)$ to copper nanoparticles (CuNPs) (Figure 3). 


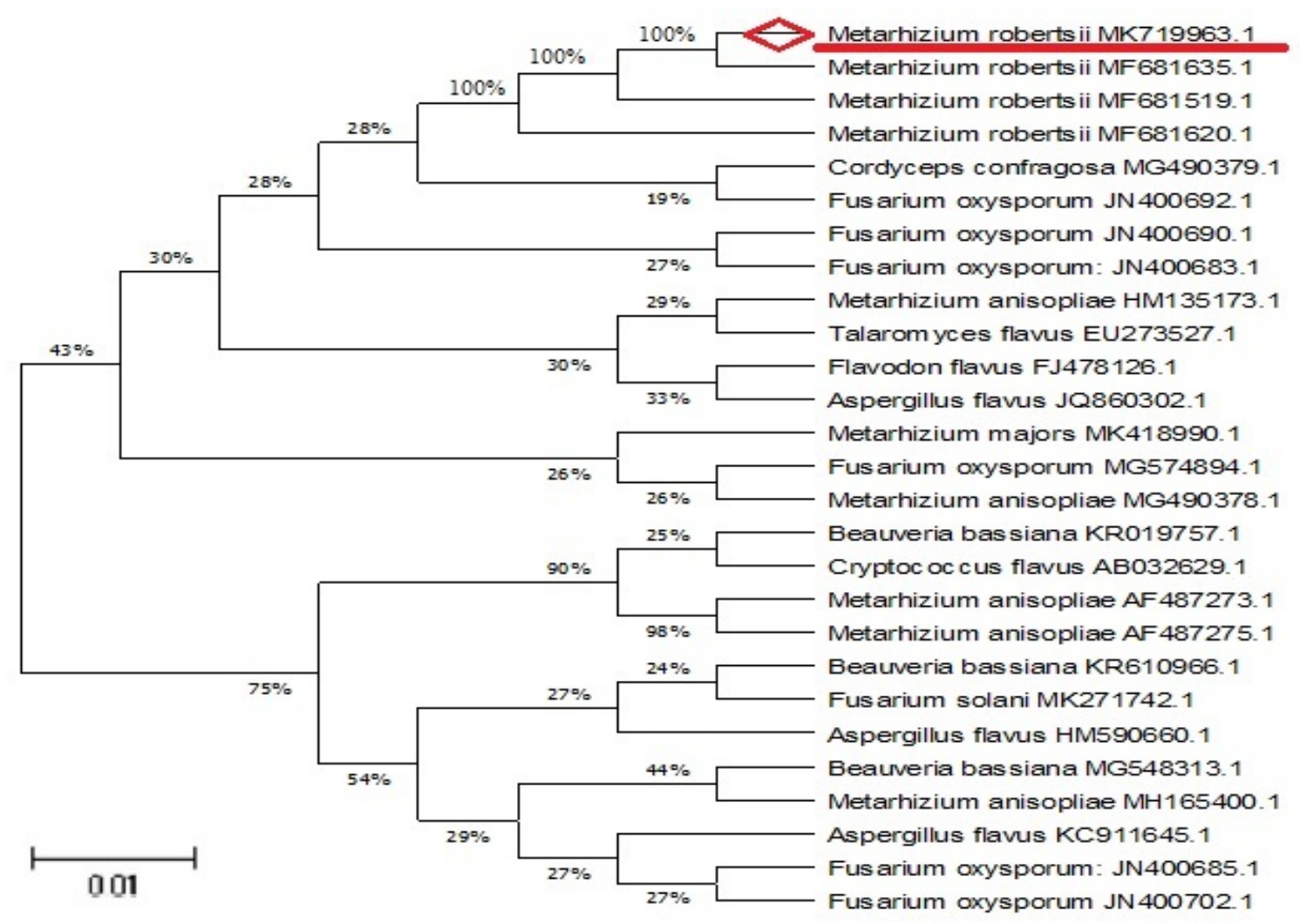

Figure 2. Neighbor-joining tree of the M. robertsii (MK719963.1) species closely related to the M. robertsii fungi.

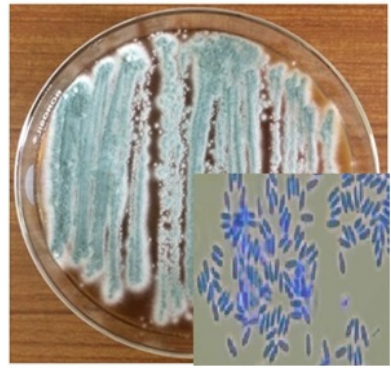

Metarhizium robertsii

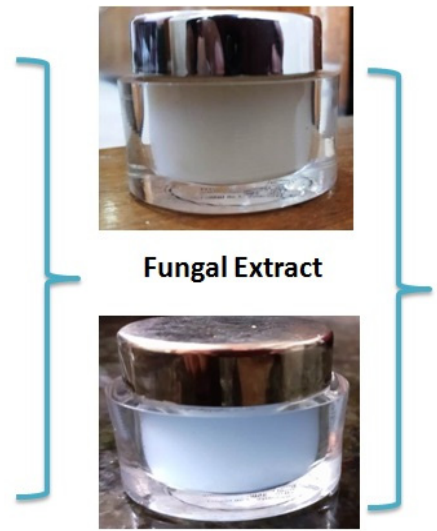

$1 \mathrm{Mm}$ copper sulphate solution

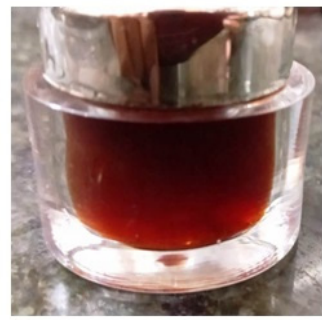

CuNPs

Figure 3. Synthesis of copper nanoparticles.

\subsection{UV-Vis Spectrophotometer Analysis}

The CuNPs had a strong absorption peak at $670 \mathrm{~nm}$ (Figure S1A).

\subsection{Fourier Transform Infrared Spectroscopy (FTIR) Analysis}

The FT-IR analysis was done for identification of functional groups in the synthesized copper nanoparticles (CuNPs). The $3441.90 \mathrm{~cm}^{-1}$ assigned to ArO-H H bonded, $2831.11 \mathrm{~cm}^{-1}$ assigned to $-\mathrm{CH} 2-, 2400.61 \mathrm{~cm}^{-1}$ assigned to $\mathrm{Ar}-\mathrm{CH}=\mathrm{CHR}$. The weaker band at $518.15 \mathrm{~cm}^{-1}$ corresponds to S-S disulfide asym in the miscellaneous group (Table S1) (Figure S1B). 


\subsection{X-Ray Diffraction (XRD) Analysis}

XRD shows the crystalline structure and high purity of CuNPs. It had 3 strongest peaks ranging at $29.4389,35.1523$ and 36.8562 . The observed strongest peak revealed the crystalline structure of copper nanoparticles (Figure S2).

\subsection{Energy Dispersive X-Ray Analysis (EDaX) Analysis}

Energy-dispersive micro analysis to gain further insight into the CuNPs' analysis of the sample was performed using the EDaX technique. The peaks ranged from $99.8 \%$ indicating the presence of CuNPs (Figure S3).

\subsection{High Resolution Scanning Electron Microscope (HR-SEM) Analysis}

HR-SEM analysis clearly shows an external morphology and crystalline structure of $\mathrm{CuNPs}$ and also revealed an exact size ranging from 15.67-62.56 nm (Figure S4).

\subsection{Atomic Force Microscope (AFM) Analysis}

Results of AFM analysis clearly showed the shape of the copper nanoparticles. Most of the nanoparticles were spherical in shape and symmetrical and were also disseminated with no aggregation. The size of the copper nanoparticles was found to be similar in size. AFM imaging technique revealed an $X$ value of $1.5 \mu \mathrm{m}$ and a $Y$ value of $2.0 \mathrm{~nm}$ and a $Z$ value in the golden image of $4.7 \mathrm{~nm}$ (Figure S5).

\subsection{Dynamic Light Scattering and Zeta Potential Studies}

Dynamic Light Scattering (DLS) method was used to conclude the nanoparticles' size distribution. Monochromatic laser diffraction collected by a photomultiplier recorded the polydispersed particles with a size ranging from $100 \mathrm{~nm}$ to $500 \mathrm{~nm}$ with a Z-average value of $56.13 \mathrm{~nm}$. Zeta potential of synthesized CuNPs was $20.3 \mathrm{mV}$ which confirms the repulsion among the particles and thus increases the stability of the nanoparticles (Figure S6).

\subsection{Mosquito Larval Bioassay}

Green copper nano-pesticide synthesized using $M$. robertsii was evaluated for mosquito larvicidal activity against $A$. stephensi, A. aegypti and C. quinquefasciatus. Results clearly showed that the CuNPs had a strong larvicidal activity against the major mosquito larvae with $\mathrm{LC}_{50}$ and $\mathrm{LC}_{90}$ values of $3.478-23.717 \mu \mathrm{g} / \mathrm{mL}$ in A. stephensi, $7.796-65.144 \mu \mathrm{g} / \mathrm{mL}$ in A. aegypti and 3.136-14.997 $\mu \mathrm{g} / \mathrm{mL}$ in C. quinquefasciatus respectively (Figure 4; Table 1). Among the mosquito larvae, the $C$. quinquefasciatus larvae were more susceptible than the other larvae.

\subsection{T. molitor Larval Bioassay}

Copper nano-pesticide synthesized from $M$. robertsii was evaluated for larvicidal activity against $T$. molitor larvae. The CuNPs had a strong larvicidal activity against $T$. molitor larvae with $\mathrm{LC}_{50}$ and $\mathrm{LC}_{90}$ values of $6.487-29.363 \mu \mathrm{g} / \mathrm{mL}$. (Figure 5; Table 2). 


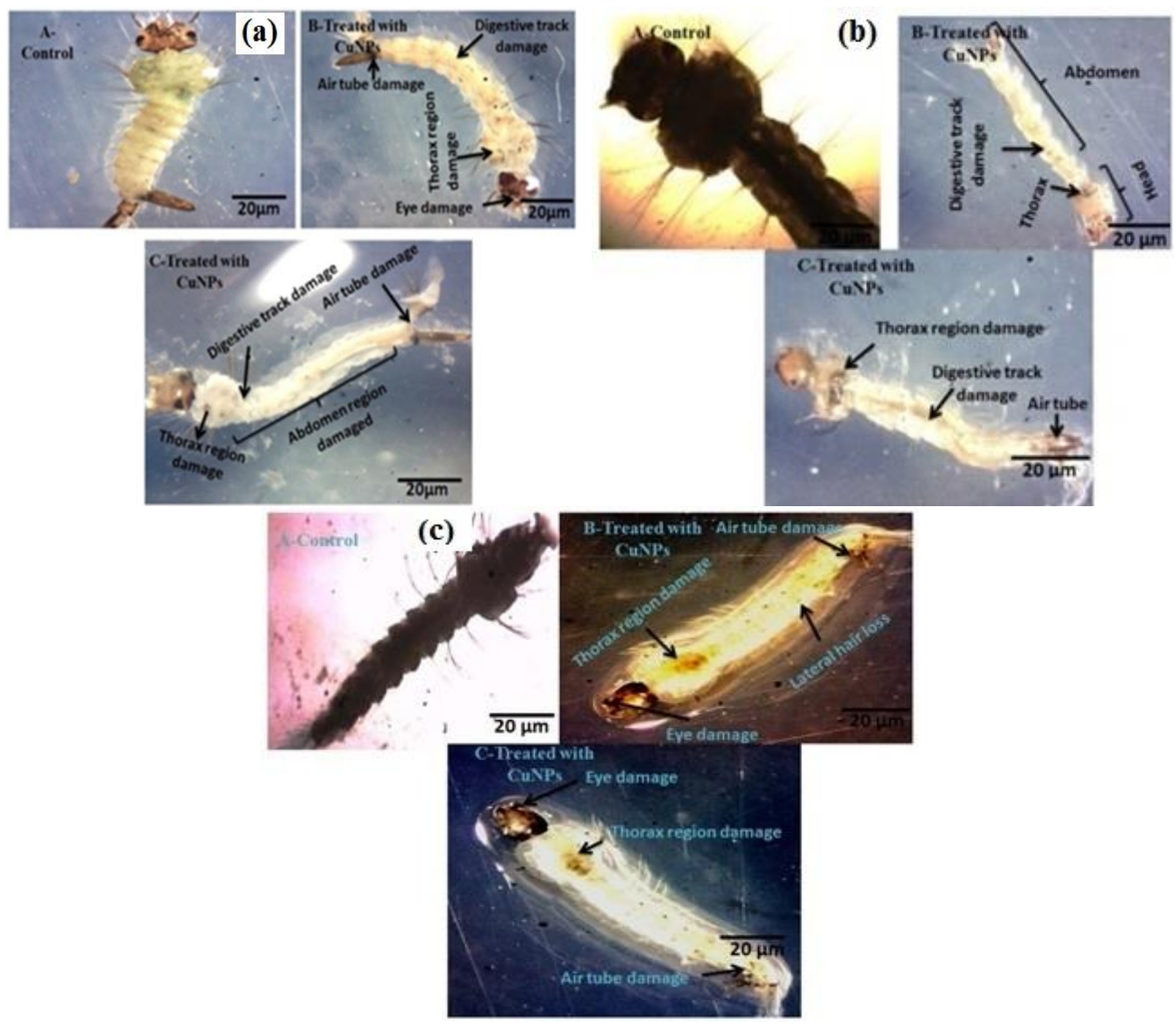

Figure 4. Green nano-pesticide synthesized from $M$. robertsii against 4 th instar larvae of $C$. quinquefasciatus, A. aegypti and A. stephensi mosquitoes: (a) C. quinquefasciatus, (b) A. aegypti, (c) A. stephensi at $24 \mathrm{~h}$ after treatment.

Table 1. Mosquitocidal activities of green cluster copper nano-pesticide synthesized from entomopathogenic fungi $M$. robertsii against 4 th instar larvae of $A$. aegypti, A. stephensi and C. quinquefasciatus at $24 \mathrm{~h}$ after treatment.

\begin{tabular}{|c|c|c|c|c|c|}
\hline $\begin{array}{l}\text { Mosquito } \\
(\mathrm{na}=450)\end{array}$ & $\begin{array}{c}\text { Concentration } \\
(\mu \mathrm{g} / \mathrm{mL})\end{array}$ & \% Mortality & $\begin{array}{c}\mathrm{LC}_{50}(\mathrm{LCL}-\mathrm{UCL}) \\
(\mu \mathrm{g} / \mathrm{mL})\end{array}$ & $\begin{array}{c}\text { LC }_{90}(\mathrm{LCL}-\mathrm{UCL}) \\
(\mu \mathrm{g} / \mathrm{mL})\end{array}$ & $\begin{array}{c}\chi^{2} \\
(\mathrm{df}=12)\end{array}$ \\
\hline \multirow{6}{*}{ A. aegypti } & Control & $2.66 \pm 0.5$ & \multirow{6}{*}{$\begin{array}{c}7.796 \\
(5.204-9.886)\end{array}$} & \multirow{6}{*}{$\begin{array}{c}65.144 \\
(39.779-188.808)\end{array}$} & \multirow{6}{*}{1.763} \\
\hline & 5 & $42.66 \pm 1.0$ & & & \\
\hline & 10 & $52.00 \pm 1.0$ & & & \\
\hline & 15 & $62.66 \pm 1.7$ & & & \\
\hline & 20 & $70.66 \pm 0.5$ & & & \\
\hline & 25 & $80.00 \pm 0.5$ & & & \\
\hline
\end{tabular}


Table 1. Cont.

\begin{tabular}{|c|c|c|c|c|c|}
\hline $\begin{array}{l}\text { Mosquito } \\
\text { (na = 450) }\end{array}$ & $\begin{array}{c}\text { Concentration } \\
(\mu \mathrm{g} / \mathrm{mL})\end{array}$ & $\%$ Mortality & $\begin{array}{c}\mathrm{LC}_{50}(\mathrm{LCL}-\mathrm{UCL}) \\
(\mu \mathrm{g} / \mathrm{mL})\end{array}$ & $\begin{array}{c}\text { LC }_{90}(\mathrm{LCL}-\mathrm{UCL}) \\
(\mu \mathrm{g} / \mathrm{mL})\end{array}$ & $\begin{array}{c}\chi^{2} \\
(\mathrm{df}=12)\end{array}$ \\
\hline \multirow{6}{*}{ A. stephensi } & Control & $1.33 \pm 0.5$ & \multirow{6}{*}{$\begin{array}{c}3.478 \\
(1.569-5.096)\end{array}$} & \multirow{6}{*}{$\begin{array}{c}23.717 \\
(17.884-40.603)\end{array}$} & \multirow{6}{*}{3.901} \\
\hline & 5 & $64.00 \pm 1.0$ & & & \\
\hline & 10 & $70.66 \pm 0.5$ & & & \\
\hline & 15 & $80.00 \pm 1.0$ & & & \\
\hline & 20 & $88.00 \pm 1.0$ & & & \\
\hline & 25 & $94.00 \pm 1.1$ & & & \\
\hline \multirow{6}{*}{ C. quinquefasciatus } & Control & $1.33 \pm 0.5$ & \multirow{6}{*}{$\begin{array}{c}3.136 \\
(0.561-6.161)\end{array}$} & \multirow{6}{*}{$\begin{array}{c}14.997 \\
(8.967-218.931)\end{array}$} & \multirow{6}{*}{6.915} \\
\hline & 5 & $69.33 \pm 1.0$ & & & \\
\hline & 10 & $78.66 \pm 0.5$ & & & \\
\hline & 15 & $85.33 \pm 0.5$ & & & \\
\hline & 20 & $93.33 \pm 0.5$ & & & \\
\hline & 25 & $100.00 \pm 0.0$ & & & \\
\hline
\end{tabular}

na $=$ total number of mosquito larvae used per each stage, 25 per replicate, three replicates were carried out, five concentrations were tested; $\mathrm{LC}_{50}=$ lethal concentration killing $50 \%$ of exposed organisms; $\mathrm{LC} 90=$ lethal concentration killing $90 \%$ of exposed organisms; $\mathrm{LCL}=95 \%$ lower confidence limits; $\mathrm{UCL}=95 \%$ upper confidence limits; $\chi^{2}=$ chi square; $\mathrm{df}=$ degrees of freedom.
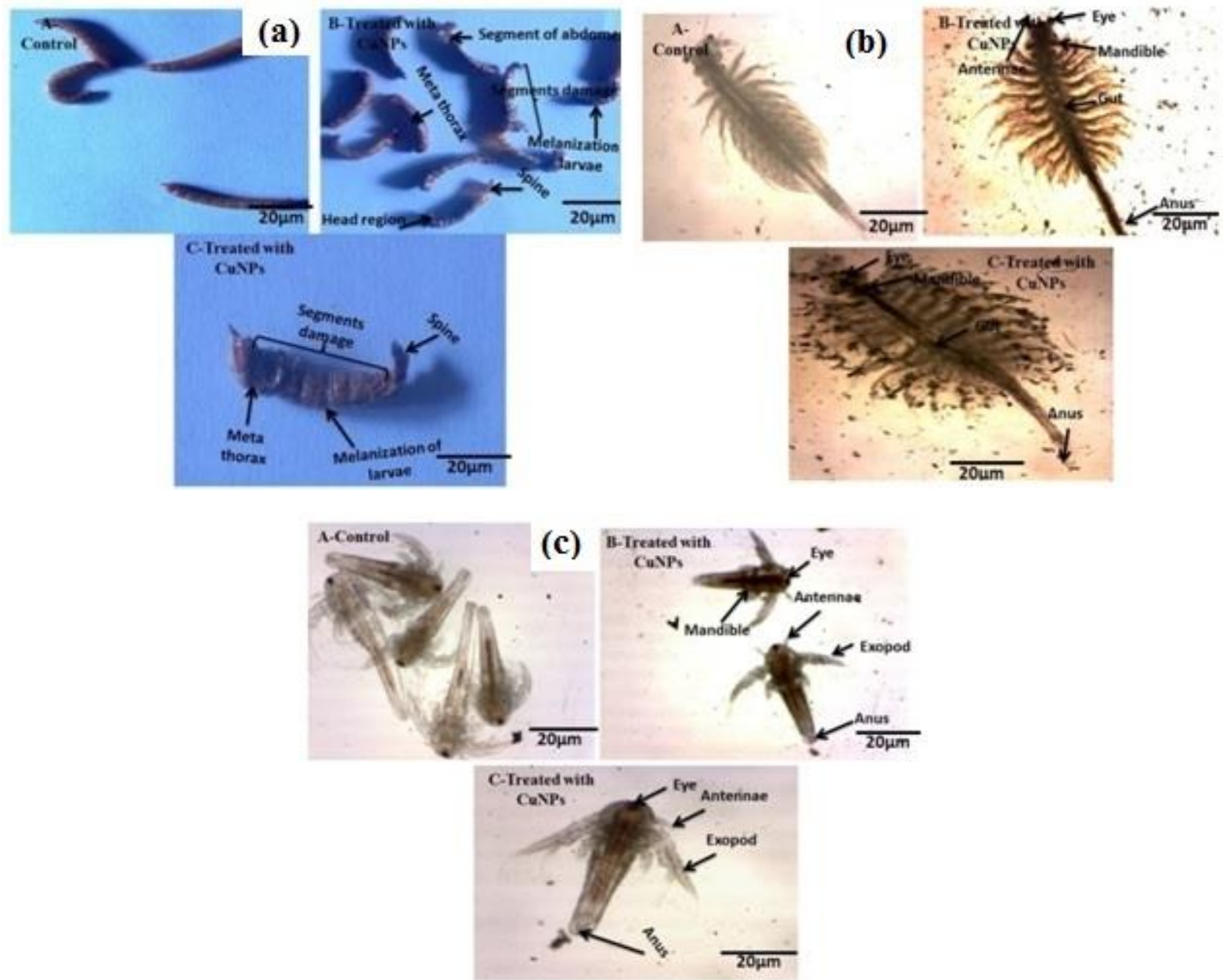

Figure 5. Effect of green copper nano-pesticide synthesized from M. robertsii against 4th instar larvae of T. molitor, A. salina and A. nauplii: (a) T. molitor, (b) A. salina, (c) A. nauplii at $24 \mathrm{~h}$ after treatment. 
Table 2. Effect of green cluster copper nano-pesticide synthesized from entomopathogenic fungi $M$. robertsii against $T$. molitor at $24 \mathrm{~h}$ after treatment.

\begin{tabular}{|c|c|c|c|c|c|}
\hline $\begin{array}{c}\text { Insect } \\
(\mathrm{na}=450)\end{array}$ & $\begin{array}{c}\text { Concentration } \\
(\mu \mathrm{g} / \mathrm{mL})\end{array}$ & $\begin{array}{c}\text { \%Mortality } \\
(\mu \mathrm{g} / \mathrm{mL})\end{array}$ & $\begin{array}{c}\mathrm{LC}_{50}(\mathrm{LCL}-\mathrm{UCL}) \\
(\mu \mathrm{g} / \mathrm{mL})\end{array}$ & $\begin{array}{c}\text { LC }_{90}(\mathrm{LCL}-\mathrm{UCL}) \\
(\mu \mathrm{g} / \mathrm{mL})\end{array}$ & $\begin{array}{c}x^{2} \\
(\mathrm{df}=12)\end{array}$ \\
\hline \multirow{6}{*}{ T. molitor } & Control & $0.00 \pm 0.0$ & \multirow{6}{*}{$\begin{array}{c}6.487 \\
(4.746-7.939)\end{array}$} & \multirow{6}{*}{$\begin{array}{c}29.363 \\
(22.833-44.577)\end{array}$} & \multirow{6}{*}{1.281} \\
\hline & 5 & $42.66 \pm 0.5$ & & & \\
\hline & 10 & $64.00 \pm 0.5$ & & & \\
\hline & 15 & $73.33 \pm 1.0$ & & & \\
\hline & 20 & $81.33 \pm 0.5$ & & & \\
\hline & 25 & $90.66 \pm 1.0$ & & & \\
\hline
\end{tabular}

na = total number of T. molitor larvae used per each stage, 25 per replicate, three replicates were carried out, five concentrations were tested; $\mathrm{LC}_{50}=$ lethal concentration killing $50 \%$ of exposed organisms; $\mathrm{LC}_{90}=$ lethal concentration killing $90 \%$ of exposed organisms; $\mathrm{LCL}=95 \%$ lower confidence limits; $\mathrm{UCL}=95 \%$ upper confidence limits; $\chi^{2}=$ chi square; $\mathrm{df}=$ degrees of freedom.

\subsection{CuNPs'Toxicity on Artemia Species}

Green copper nano-pesticide synthesized using M. robertsii was evaluated for nontoxicity efficacy on aquatic indicators such as $A$. nauplii and $A$. salina. CuNPs had a lower toxicity to $A$. nauplii and $A$. salina. The $\mathrm{LC}_{50}$ and $\mathrm{LC}_{90}$ values were $166.731-450.981 \mu \mathrm{g} / \mathrm{mL}$ in A. nauplii and $293.901-980.153 \mu \mathrm{g} / \mathrm{mL}$ in A. salina respectively (Figure 5c; Table 3). The CuNPs induced lower sublethal toxicity to $A$. nauplii and $A$. salina compared to mosquito larvae and stored grain pests (Figure $5 b$ ).

Table 3. Non-target effect of green cluster copper nano-pesticide synthesized from entomopathogenic fungi $M$. robertsii against $A$. nauplii and $A$. salina at $24 \mathrm{~h}$ after treatment.

\begin{tabular}{|c|c|c|c|c|c|}
\hline $\begin{array}{c}\text { Organisms } \\
(\mathrm{na}=375)\end{array}$ & $\begin{array}{l}\text { Concentration } \\
(\mu \mathrm{g} / \mathrm{mL})\end{array}$ & $\begin{array}{c}\text { \%Mortality } \\
(\mu \mathrm{g} / \mathrm{mL})\end{array}$ & $\begin{array}{c}\mathrm{LC}_{50}(\mathrm{LCL}-\mathrm{UCL}) \\
(\mu \mathrm{g} / \mathrm{mL})\end{array}$ & $\begin{array}{c}\mathrm{LC}_{90}(\mathrm{LCL}-\mathrm{UCL}) \\
(\mu \mathrm{g} / \mathrm{mL})\end{array}$ & $\begin{array}{c}\chi^{2} \\
(\mathrm{df}=12)\end{array}$ \\
\hline \multirow{6}{*}{ A. nauplii } & Control & $0.00 \pm 0.0$ & \multirow{6}{*}{$\begin{array}{c}166.731 \\
(117.925- \\
308.963)\end{array}$} & \multirow{6}{*}{$\begin{array}{c}450.981 \\
(380.110- \\
490.000)\end{array}$} & \multirow{6}{*}{0.833} \\
\hline & 5 & $34.66 \pm 0.5$ & & & \\
\hline & 10 & $40.00 \pm 1.0$ & & & \\
\hline & 15 & $45.33 \pm 0.5$ & & & \\
\hline & 20 & $53.33 \pm 0.5$ & & & \\
\hline & 25 & $58.66 \pm 1.1$ & & & \\
\hline \multirow{6}{*}{ A. salina } & Control & $1.33 \pm 0.5$ & \multirow{6}{*}{$\begin{array}{c}293.901 \\
(200.295- \\
891.950)\end{array}$} & \multirow{6}{*}{$\begin{array}{c}980.153 \\
(890.431- \\
990.001)\end{array}$} & \multirow{6}{*}{1.055} \\
\hline & 5 & $25.33 \pm 0.7$ & & & \\
\hline & 10 & $29.33 \pm 0.5$ & & & \\
\hline & 15 & $37.33 \pm 1.0$ & & & \\
\hline & 20 & $42.66 \pm 0.5$ & & & \\
\hline & 25 & $50.66 \pm 1.0$ & & & \\
\hline
\end{tabular}

\subsection{CuNPs'Toxicity on Earthworm and Histopathology}

E. eugeniae and E. andrei are soil toxicological bio-indicator species. Post treatment, after 30 days, there was low mortality observed in the CuNPs' treatment. The low sublethal effects of CuNPs were observed in gut tissues. The CuNPs which treated earthworm gut cells were normal, and a regular epithelial surface was observed. There was no cellular 
debris and the nuclei were round in shape. Similar results were observed in the controls (Figure 6; Table 4).
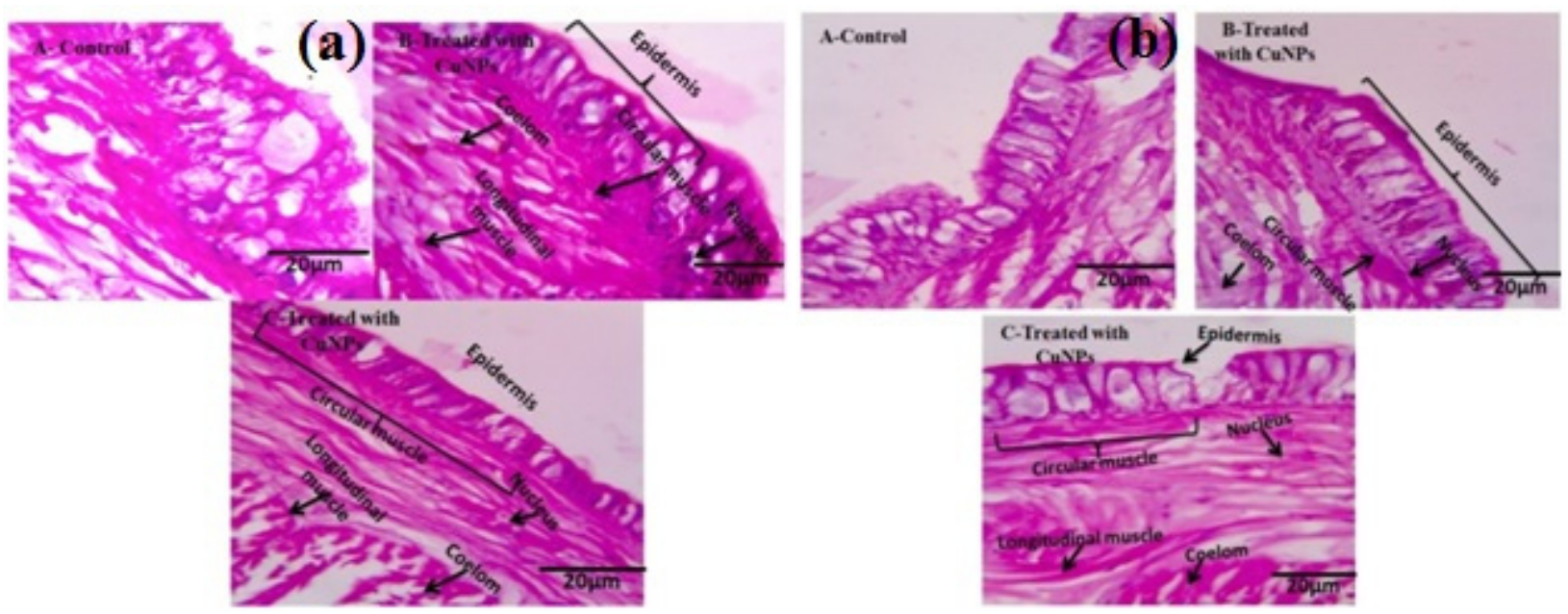

Figure 6. Histopathological studies of green copper nano-pesticide synthesized from M. robertsii against E. eugeniae and E. andrei: (a) E. eugeniae, (b) E. andrei with CuNPs at $24 \mathrm{~h}$ after treatment with CuNPs.

Table 4. Non-target effect of green cluster copper nano-pesticide synthesized from entomopathogenic fungi $M$. robertsii against E. eugeniae and E. andrei at 30 days after treatment.

\begin{tabular}{|c|c|c|c|c|c|}
\hline $\begin{array}{l}\text { Earthworm } \\
(\text { na }=270)\end{array}$ & $\begin{array}{l}\text { Concentration } \\
(\mu \mathrm{g} / \mathrm{mL})\end{array}$ & $\begin{array}{l}\text { \%Mortality } \\
(\mu \mathrm{g} / \mathrm{mL})\end{array}$ & $\begin{array}{c}\mathrm{LC}_{50}(\mathrm{LCL}-\mathrm{UCL}) \\
(\mu \mathrm{g} / \mathrm{mL})\end{array}$ & $\begin{array}{c}\mathrm{LC}_{90}(\mathrm{LCL}-\mathrm{UCL}) \\
(\mu \mathrm{g} / \mathrm{mL})\end{array}$ & $\begin{array}{c}\chi^{2} \\
(\mathrm{df}=12)\end{array}$ \\
\hline \multirow{6}{*}{ E. eugeniae } & Control & $0.00 \pm 0.0$ & \multirow{6}{*}{$\begin{array}{c}425.957 \\
(305.941- \\
1296.415)\end{array}$} & \multirow{6}{*}{$\begin{array}{l}1091.230 \\
(567.447- \\
1125.151)\end{array}$} & \multirow{6}{*}{0.208} \\
\hline & 5 & $0.00 \pm 0.0$ & & & \\
\hline & 10 & $2.22 \pm 0.5$ & & & \\
\hline & 15 & $8.88 \pm 1.0$ & & & \\
\hline & 20 & $15.55 \pm 1.0$ & & & \\
\hline & 25 & $22.22 \pm 0.5$ & & & \\
\hline \multirow{6}{*}{ E. andrei } & Control & $0.00 \pm 0.0$ & \multirow{6}{*}{$\begin{array}{c}498.178 \\
(330.697- \\
2893.119)\end{array}$} & \multirow{6}{*}{$\begin{array}{l}1328.375 \\
(610.925- \\
1395.110)\end{array}$} & \multirow{6}{*}{0.575} \\
\hline & 5 & $0.00 \pm 0.0$ & & & \\
\hline & 10 & $2.22 \pm 0.5$ & & & \\
\hline & 15 & $6.66 \pm 0.5$ & & & \\
\hline & 20 & $8.88 \pm 1.7$ & & & \\
\hline & 25 & $20.00 \pm 1.0$ & & & \\
\hline
\end{tabular}

na = total number of earthworms used per each stage, 15 per replicate, three replicates were carried out, five concentrations were tested; $\mathrm{LC}_{50}=$ lethal concentration killing $50 \%$ of exposed organisms; $\mathrm{LC}_{90}=$ lethal concentration killing 90\% of exposed organisms; LCL $=95 \%$ lower confidence limits; $\mathrm{UCL}=95 \%$ upper confidence limits; $\chi^{2}=$ chi square; $\mathrm{df}=$ degrees of freedom.

\section{Discussion}

In this study, the $M$. robertsii entomopathogenic fungal culture was isolated using insect bait method $[9,23]$. The fungi were light green; the conidial structure was slender in shape. Similarly, the conidia were green and also slender in shape as previously reported $[2,3]$. Based on morphological characteristics, the fungi were confirmed as Metarhizium species. Based on the molecular characterization results, the M. robertsii genomic DNA size range is $900 \mathrm{bp}$ and was amplified using 18s rDNA primer. Similarly, the study in [2] reported that $M$. anisopliae-amplified DNA molecule had $1000 \mathrm{bp}$ in size. The M. robertsii 18s rDNA sequence had $100 \%$ similarity with $M$. robertsii. Based on this similarity, we confirmed the isolated entomopathogenic fungi were M. robertsii. Vector-borne diseases are considered to be major problems to public health worldwide $[2,3,16]$. Synthetic chemical insecticide was effective against agricultural and medical pests, but there were challenges faced such as insecticide resistance [17]. Continuous use of chemical insecticides has hampered the insect control programs and formed many insecticide resistance problems [28]. Use of 
nano-materials in insect control has gained interest because of its eco-friendliness and biocompatibility [10,29].

UV-Vis spectroscopy analysis has the best techniques for preliminary confirmation of the nanoparticles. Copper nanoparticles synthesized from the $M$. robertsii culture filtrate had an absorption maxima range at $670 \mathrm{~nm}$, indicating the synthesis of copper nanoparticles. Similarly, Kalaimurugan et al. [30] reported that the pathogenic bacteria P. fluorescens-YPS3derived nanoparticles produced an identical range of absorption range. FT-IR analysis was done for identification of the functional groups present in the synthesized copper nanoparticles (CuNPs). The $3441.90 \mathrm{~cm}^{-1}$ assigned to ArO- $\mathrm{H} \mathrm{H}$ bonded, $2831.11 \mathrm{~cm}^{-1}$ was assigned to $-\mathrm{CH} 2-, 2400.61 \mathrm{~cm}^{-1}$ and assigned to $\mathrm{Ar}-\mathrm{CH}=\mathrm{CHR}$. The weaker band at $518.15 \mathrm{~cm}^{-1}$ corresponds to S-S disulfide asym. This vibrational assignment clearly shows several strong functional groups such as phenols, alkanes, carboxylic acids and aromatics functional groups. Similarly, Logeswaran and others reported a similar kind of functional groups such as carboxylic acids, alkanes, carboxylic acids and aromatics in ethyl acetate crude extract of G. applantum. EDaX peak around $99.8 \%$ to the binding energies of copper indicates the reaction product is present in the pure form of copper nanoparticles and also contains a weak signal from the oxygen [31]. The EDaX record for CuNPs' synthesized fungal culture filtrate showed a strong signal of copper from $2 \mathrm{keV}$. X-ray emission from carbohydrates/proteins/enzymes presented within the insect pathogenic fungi. A similar level of binding energy was reported in the silver nanoparticles synthesized from the entomopathogenic fungal- and bacterial-derived nanoparticles [8,31].

The results of XRD showed the presence of the crystalline size and shape of the synthesized copper nanoparticles using the M. robertsii culture filtrate as a reducing agent, and thus confirming the crystallization of the synthesized copper nanoparticles. The entomopathogenic fungi $M$. anisopliae-derived silver nanoparticles produced a similar kind of crystalline size and shape of the nanoparticles from the fungal culture filtrates [32]. The particle size was resolute by dynamic light scattering (DLS) dimension. Laser diffraction studies revealed that particle size obtained from highly dispersed mixture was in the range of $15.67-62.56 \mathrm{~nm}$. The zeta potential capacity indicates negative charges $(14.35 \mathrm{mV})$ on the copper nanoparticles. Previous research findings reported similar size range of the nanoparticles from culture filtrate-derived nanoparticles with the size range of 30-150 $\mathrm{nm}$ [33].

HR-SEM analysis showed that nanoparticles are spherical in shape and the size ranged from 15.67-62.56 nm. Sarker et al. [33] reported that SEM analysis recorded dissimilar sizes of nanoparticles from the bacteria and fungi culture filtrate-derived selenium particles. Results of AFM analysis characterized the shape. Most of the nanoparticles were spherical in shape, symmetrical and disseminated with no aggregation. The size of the copper nanoparticles was found to be similar in size. AFM imaging technique reveals $X$ value $1.5 \mu \mathrm{m}$ and $\mathrm{Y}$ value was $2.0 \mathrm{~nm}$ with $\mathrm{Z}$ value in the golden image being $4.7 \mathrm{~nm}$.

Our results on $M$. robertsii culture filtrate-derived green pesticides (CuNPs) showed strong larvicidal activity with low $\mathrm{LC}_{50}$ and $\mathrm{LC}_{90}$ values against $A$. stephensi, $A$. aegypti and C. quinquefasciatus mosquitoes, and 4th instar larvae of T. molitor stored grain pest. Similar reports on entomopathogenic fungi- and bacteria-derived silver nanoparticles produced remarkable levels of mosquito larvicidal activity against 4th instar $A$. stephensi, A. aegypti and $C$. quinquefasciatus mosquitoes under laboratory conditions $[8,30]$. The entomopathogenic fungi Beauveria bassiana ethyl acetate-derived chemical constituents produced high damage inside of the C. quinquefasciatus mosquito larvae [10]; similarly, the combination of insect pathogenic fungal toxins and synthetic chemical constituents produced toxicity against three major mosquito species under laboratory conditions [9].

The 4th instar T. molitor was highly susceptible to the $M$. robertsii culture filtratederived green pesticides (CuNPs) at $24 \mathrm{~h}$ post treatment under laboratory conditions. Similarly, garlic-derived secondary metabolites/essential oils caused a reduced respiration rate of T. molitor within $3 \mathrm{~h}$ after treatment, probably similar in behavior to their locomotor activity. The respiratory speed and mass of the insect body can stand for the sum of the 
energy demands of the physiological response of $T$. molitor that are essential to create a protection response to chemical constituents $[34,35]$.

CuNPs showed a lower sublethal toxicity to the non-target organisms E. eugeniae, $E$. andrei, A. nauplii and A. salina. Green copper nano-pesticides synthesized using $M$. robertsii were evaluated for non-toxicity effect on aquatic indicators such as A. nauplii and A. salina. Our results showed that CuNPs had a lower toxicity to $A$. nauplii and $A$. salina. The CuNPs induced lower sublethal toxicity to $A$. nauplii and A. salina compared to mosquito larvae and the stored grain pest. Similarly $M$. anisopliae derived ethyl acetate chemical constituent caused lower toxicity and no behavioral changes against $A$. nauplii $24 \mathrm{~h}$ after treatment [3].

E. eugeniae and E. andrei are soil toxicological bio-indicator species. Thirty days after treatment, a low level of mortality was observed in the CuNPs' treatment. However, there was a low level of sublethal effects of CuNPs that caused tissue damage. The CuNPstreated earthworm gut cells were normal, regular epithelial surface was observed, there was no cellular debris and the nucleus was round in shape. The same results were observed in the controls. Vivekanandhan and colleagues found similar results from Metarhizium anisopliae-derived chemical constituents which produced lower toxic effects on the nontarget organism E. eugeniae 30 days after treatment under laboratory conditions [3].

\section{Conclusions}

Currently, environmental safety is of paramount importance in protection against pollution to guarantee safety for humans and other animals. In the present research, entomopathogenic fungal-derived CuNPs have been found highly useful for controlling mosquito larvae populations in the field. The green synthesized nanoparticles have several advantages such as easily degradable, cheaper and eco-friendly, not toxic to non-target organisms and they are plant-derived. CuNPs can be easily synthesized and used as an effective nano-insecticide for mosquito control. In the present study, the copper nanoparticles were synthesized using $M$. robertsii. The copper nanoparticles were tested for their larvicidal activity on 4th instar A. stephensi, A. aegypti, C. quinquefasciatus and T. molitor and were non-toxic to bio-indicators. Our results show that green synthesized copper nanoparticles (CuNPs) show they are toxic to A. stephensi, A. aegypti and C. quinquefasciatus and less toxic to E. eugeniae, E. andrei, A. nauplii and A. salina. From this study we concluded that $M$. robertsii-derived copper nanoparticles (CuNPs) were safer and not toxic to non-target organisms.

Supplementary Materials: The following are available online at https:/ /www.mdpi.com/article/10 .3390/ijerph181910536/s1, Figure S1: (A) UV-visible Spectrophotometer absorption range at $670 \mathrm{~nm}$; (B) FT-IR analysis shows a several functional groups from green cluster copper nano-pesticide synthesized from M. robertsii, Figure S2: XRD shows 3 strongest peak values at 29.4389, 35.1523 and 36.8562 this strongest peak value tells about the crystalline structure of copper nanoparticles, Figure S3: EDaX image gave an exact elementary composition and the ranges from 0 to $20 \mathrm{keV}$. It shows some elements such as $\mathrm{O}$ and CU, Figure S4: SEM analysis of green synthesis $\mathrm{CuNPs}$ that show sizes ranging from 15.67-62.56 nm, Figure S5: AFM analysis of green cluster copper nano-pesticide synthesized M. robertsii, A. $2.5 \mu \mathrm{m}$ resolution studies of $0-0.475 \mathrm{~nm}$ size, spherical shaped, poly dispersed particles, Figure S6: Zeta potential and DLS of green synthesized copper nanoparticles, Table S1: FT-IR functional group's identification of green cluster copper nano-pesticide synthesized from entomopathogenic fungi $M$. robertsii.

Author Contributions: Conceptualization, P.V., K.S. and P.K.; Data Observation, P.V., K.S., A.T., E.J.K., A.R., S.P. and P.K.; Formal analysis, P.V., K.S. and P.K.; Investigation, P.V.; Methodology, P.V. and K.S.; Resources, K.S.; Supervision, E.J.K. and P.K.; Validation, P.V., K.S., A.T. and E.J.K.; Visualization, K.S. and P.K.; Writing—original draft, P.V., K.S., E.J.K., A.R., S.P. and P.K.; Writing—review and editing, P.V., K.S., A.T., E.J.K., A.R., S.P. and P.K. All authors have read and agreed to the published version of the manuscript.

Funding: This research received no external funding. 
Acknowledgments: The authors thank Periyar University, Tamil, Nadu, India, for making available the infrastructure and resources for this study. We would like to acknowledge the Teaching Assistant and Research Assistant (TA/RA) and Pres-idential scholarships from the Graduate School, Chiang Mai University. This research was partially supported by Chiang Mai University, Thailand.

Conflicts of Interest: The authors declare that they have no conflict of interest.

\section{References}

1. Coelho, W.M.D.; Coêlho, J.d.C.A.; Bresciani, K.D.S.; Buzetti, W.A.S. Biological control of Anopheles darlingi, Aedes aegypti and Culex quinquefasciatus larvae using shrimps. Para. Epidemiol. 2017, 2, 91-96. [CrossRef]

2. Vivekanandhan, P.; Bedini, S.; Shivakumar, M.S. Isolation and identification of entomopathogenic fungus from Eastern Ghats of South Indian forest soil and their efficacy as biopesticide for mosquito control. Parasitol. Int. 2020, 76, 102099. [CrossRef]

3. Vivekanandhan, P.; Swathy, K.; Kalaimurugan, D.; Ramachandran, M.; Yuvaraj, A.; Kumar, A.N.; Manikandan, A.T.; Poovarasan, N.; Shivakumar, M.S.; Kweka, E.J. Larvicidal toxicity of Metarhizium anisopliae metabolites against three mosquito species and non-targeting organ-isms. PLoS ONE 2020, 15, e0232172. [CrossRef]

4. Kim, S.Y.; Kim, H.G.; Yoon, H.J.; Lee, K.Y.; Kim, N.J. Nutritional analysis of alternative feed ingredients and their effects on the larval growth of Tenebrio molitor (Coleoptera: Tenebrionidae). J. Entomol. Res. 2017, 47, 194-202. [CrossRef]

5. Cosimi, S.; Rossi, E.; Cioni, P.; Canale, A. Bioactivity and qualitative analysis of some essential oils from Mediterranean plants against stored-product pests: Evaluation of repellency against Sitophilus zeamais Motschulsky, Cryptolestes ferrugineus (Stephens) and Tenebrio molitor (L.). J. Stored Prod. Res. 2009, 45, 125-132. [CrossRef]

6. Lazzari, S.M.; Lazzari, F.A. Insect pests in stored grain. In Insect Bioecology and Nutrition for Integrated Pest Management: Antônio Ricardo Panizzi; Parra, J.R.P., Ed.; Taylor Francis: Boca Raton, FL, USA, 2012; pp. 417-448.

7. Zhang, H.; Hong, X.; Yan, S.; Zha, J.; Qin, J. Environmentally relevant concentrations of bifenthrin induce changes in behavior biomarkers, histological characteristics, and the transcriptome in Corbicula fluminea. Sci. Total Environ. 2020, 728, 138821. [CrossRef] [PubMed]

8. Vivekanandhan, P.; Deepa, S.; Kweka, E.J.; Shivakumar, M.S. Toxicity of Fusarium oxysporum-VKFO-01 derived silver nanoparticles as potential inseciticide against three mosquito vector species (Diptera: Culicidae). J. Clust. Sci. 2018, 29, 1139-1149. [CrossRef]

9. Vivekanandhan, P.; Karthi, S.; Shivakumar, M.S.; Benelli, G. Synergistic effect of entomopathogenic fungus Fusarium oxysporum extract in combination with temephos against three major mosquito vectors. Pathog. Glob. Health 2018, 112, 37-46. [CrossRef] [PubMed]

10. Vivekanandhan, P.; Kavitha, T.; Karthi, S.; Senthil-Nathan, S.; Shivakumar, M.S. Toxicity of Beauveria bassiana-28 Mycelial Extracts on Larvae of Culex quinquefasciatus Mosquito (Diptera: Culicidae). Int. J. Environ. Res. Public Health 2018, 15, 440. [CrossRef]

11. Garrido-Jurado, I.; Fernández-Bravo, M.; Campos, C.; Quesada-Moraga, E. Diversity of entomopathogenic Hypocreales in soil and phylloplanes of five Mediterranean cropping systems. J. Invertebr. Pathol. 2015, 130, 97-106. [CrossRef] [PubMed]

12. Clifton, E.H.; Jaronski, S.T.; Hajek, A.E. Virulence of Commercialized Fungal Entomopathogens against Asian Longhorned Beetle (Coleoptera: Cerambycidae). J. Insect Sci. 2020, 20. [CrossRef] [PubMed]

13. De Faria, M.R.; Wraight, S.P. Mycoinsecticides and mycoacaricides: A comprehensive list with worldwide coverage and international classification of formulation types. J. Biol. Control 2007, 43, 237-256. [CrossRef]

14. Govindarajan, M.; Rajeswary, M.; Muthukumaran, U.; Hoti, S.; Khater, H.F.; Benelli, G. Single-step biosynthesis and characterization of silver nanoparticles using Zornia diphylla leaves: A potent eco-friendly tool against malaria and arbovirus vectors. J. Photochem. Photobiol. B Biol. 2016, 161, 482-489. [CrossRef] [PubMed]

15. Ishwarya, R.; Vaseeharan, B.; Anuradha, R.; Rekha, R.; Govindarajan, M.; Alharbi, N.S.; Kadaikunnan, S.; Khaled, J.M.; Benelli, G. Eco-friendly fabrication of Ag nanostructures using the seed extract of Pedalium murex, an ancient Indian medicinal plant: Histopathological effects on the Zika virus vector Aedes aegypti and inhibition of biofilm-forming pathogenic bacteria. J. Photochem. Photobiol. B Biol. 2017, 174, 133-143. [CrossRef]

16. Benelli, G.; Duggan, M.F. Management of arthropod vector data-Social and ecological dynamics facing the One Health perspective. Acta Trop. 2018, 182, 80-91. [CrossRef]

17. Kweka, E.J.; Mazigo, H.D.; Lyaruu, L.J.; Mausa, E.A.; Venter, N.; Mahande, A.M.; Coetzee, M. Anopheline Mosquito Species Composition, Kdr Mutation Frequency, and Parasite Infectivity Status in Northern Tanzania. J. Med. Entomol. 2020, 57, 933-938. [CrossRef]

18. Zimmermann, G. The entomopathogenic fungus Metarhizium anisopliae and its potential as a biocontrol agent. J. Pestic. Sci. 1993, 37, 375-379. [CrossRef]

19. Strasser, H.; Vey, A.; Butt, T.M. Are there any risks in using entomopathogenic fungi for pest control, with particular reference to the bioactive metabolites of of Metarhizium, Tolypocladium and Beauveria species? Biocontrol Sci. Technol. 2000, 10, 717-735. [CrossRef]

20. Chen, D.; Ye, G.; Yang, C.; Chen, Y.; Wu, Y. The effect of high temperature on the insecticidal properties of Bt cotton. Environ. Exp. Bot. 2005, 53, 333-342. [CrossRef]

21. Bouché, M.B.; Al-Addan, F.; Cortez, J.; Hammed, R.; Heidet, J.-C.; Ferrière, G.; Mazaud, D.; Samih, M.J.S.B. Role of earthworms in the N cycle: A falsifiable assessment. Biochemistry 1997, 29, 375-380. [CrossRef] 
22. Naidu, J.R.; Ismail, R.; Sasidharan, S. Acute oral toxicity and brine shrimp lethality of methanol extract of Mentha spicata L (Lamiaceae). Trop. J. Pharm. Res. 2014, 13, 101-107. [CrossRef]

23. Ansari, M.A.; Butt, T.M. Susceptibility of different developmental stages of large pine weevil Hylobius abietis (Coleoptera: Curculionidae) to entomopathogenic fungi and effect of fungal infection to adult weevils by formulation and application methods. J. Invertebr. Pathol. 2012, 111, 33-40. [CrossRef] [PubMed]

24. Ragavendran, C.; Dubey, N.K.; Natarajan, D. Beauveria bassiana (Clavicipitaceae): A potent fungal agent for controlling mosquito vectors of Anopheles stephensi, Culex quinquefasciatus and Aedes aegypti (Diptera: Culicidae). RSC Adv. 2017, 7, 3838-3851. [CrossRef]

25. WHO. Guidelines for Laboratory and Field Testing of Mosquito Larvicides; World Health Organization: Geneva, The Netherland, 2005.

26. OECD. OECD Guideline for Testing of Chemicals; Earthworm Acute Toxicity: Paris, France, 1984.

27. Abbott, W.S. A method of computing the effectiveness of an insecticide. J. Econ. Entomol. 1925, 18, 265-266. [CrossRef]

28. Mathias, L.; Baraka, V.; Philbert, A.; Innocent, E.; Francis, F.; Nkwengulila, G.; Kweka, E.J. Habitat productivity and pyrethroid susceptibility status of Aedes aegypti mosquitoes in Dar es Salaam, Tanzania. Infect. Dis. Poverty 2017, 6, 102. [CrossRef] [PubMed]

29. Benelli, G.; Lukehart, C.M. Applications of green-synthesized nanoparticles in pharmacology, parasitology and entomology. J. Clust. Sci. 2017, 28, 1-2. [CrossRef]

30. Kalaimurugan, D.; Vivekanandhan, P.; Sivasankar, P.; Durairaj, K.; Senthilkumar, P.; Shivakumar, M.S.; Venkatesan, S. Larvicidal activity of silver nanoparticles synthesized by Pseudomonas fluorescens YPS3 isolated from the Eastern Ghats of India. J. Clust. Sci. 2019, 30, 225-233. [CrossRef]

31. Logeswaran, C.; Vivekanandhan, P.; Shivakumar, M. Chemical constituents of thermal stress induced Ganoderma applantum(Per.) secondary metabolites on larvae of Anopheles stephensi, Aedes aegypti and Culex quinquefasciatus and histopathological effects in mosquito larvae. Biocatal. Agric. Biotechnol. 2019, 20, 101253. [CrossRef]

32. Amerasan, D.; Nataraj, T.; Murugan, K.; Panneerselvam, C.; Madhiyazhagan, P.; Nicoletti, M.; Benelli, G. Myco-synthesis of silver nanoparticles using Metarhizium anisopliae against the rural malaria vector Anopheles culicifacies Giles (Diptera: Culicidae). J. Pest Sci. 2016, 89, 249-256. [CrossRef]

33. Sarkar, J.; Chattopadhyay, D.; Patra, S.; Singh Deo, S.; Sinha, S.; Ghosh, M.; Mukherjee, A.; Acharya, K. Alternaria alternata mediated synthesis of protein capped silver nanoparticles and their genotoxic activity. Dig. J. Nanomater. Biostructures 2011, 6 , 563-573.

34. Correa, Y.D.C.G.; Faroni, L.R.; Haddi, K.; Oliveira, E.E.; Pereira, E.J.G. Locomotory and physiological responses induced by clove and cinnamon essential oils in the maize weevil Sitophilus zeamais. Pestic. Biochem. Physiol. 2015, 125, 31-37. [CrossRef] [PubMed]

35. Guedes, R.N.C.; Oliveira, E.; Guedes, N.; Ribeiro, B.; Serrão, J. Cost and mitigation of insecticide resistance in the maize weevil, Sitophilus zeamais. J. Physiol. Entomol. 2006, 31, 30-38. [CrossRef] 